\title{
An unpresented approach to ameliorate swine waste contamination
}

\author{
W C Chen* and TYYeh \\ Department of Civil and Environmental Engineering, National University of Kaohsiung, Taiwan
}

\begin{abstract}
Piggery waste is one the tree major water pollution sources in Taiwan. Piggery waste should be viewed as resource and not waste. Conventionally, three stage wastewater treatments are too costly and hard to operate. Direct application to soil can be a remedy if the application rate is careful managed. Generally, wastewater from the piggery industry is treated in three stages: liquid solid separation, anaerobic digestion and then aerobic treatment. However, this process is difficult due to high cost and difficult operation. Therefore, a feasible method was to establish a centralized methane production facility for the treatment of piggery industrial waste. The products after treated like methane and fertilize are utilized as clean and environmentally friendly products. Methane can be used for cooking or electricity generation. This is a new direction suitable for sustainable development. Three stage piggery waste water treatment including soil liquid separation, anaerobic digestion and then aerobic treatment which is not well received and popular due to costly and difficult operation in Taiwan. Particularly, the anaerobic component is always a headache. Taiwan EPA ambitiously launches piggery manure direct apply to soil policy. It might the panacea to water pollution control. The feasible approach is to set a centralized methane production facility to purify, electricity as well as heat generation, and gay for motor. With the major pollutants such as odors, BOD, TN and TS, waste from the piggery industry has been seriously affecting the environment in Taiwan. However, if this amount of waste is properly treated, it will bring great benefits and can be considered as a resource.
\end{abstract}

\section{Introduction}

Currently, there are 5,539,130 capita pigs in Taiwan which located in pintung, yulin, chunghwa, tainan, chayi, kaohsiunf townships. The types of piggery industries are enormously large and congested. The qualities of piggery wastewater are high SS, high organic matters, and high ammonium nitrogen. In addition, the piggery wastewater has strong odor and quality fluctuated. Piggery wastewaters encompass high nutrient loading. If improper managed, it will pollute aquatic environment and induce serious eutrophication. The smell piggery waste will deteriorate living standard and affect human health. Anaerobic biological treatment processes dealing with high organic loading piggery wastewater possess low energy consumption, methane resource recovery, high treatment capability, low sludge generation, high toxic substance endurance. It has become the popular research topic in water industries [1].

\section{Treatment of piggery waste}

The process of wastewater treatment of the piggery industries has three main stages. They are soil liquid separation, anaerobic digestion and aerobic treatment.

Soil liquid separation: The primary function of solid liquid separation is scum generation reducing and treatment capacity levying. It separates manure and pie which can lessen treatment laboring significantly. Generally speaking, 15-30\% BOD removal and 50\% SS removal. The screen is $0.5 \mathrm{~mm}$ first following by $0.3 \mathrm{~mm}$. The second screen has trustworthy treatment capability.

\section{Anaerobic fermentation}

Anaerobic fermentation can degrade complex organic substance into simple $\mathrm{CH} 4, \mathrm{CO} 2$ under anoxic condition. The advantages of anaerobic fermentation are low sludge generation, methane resource recovery, high organic loading endurance, great treated water production, save oxygen, killing pathogen and virus. However, the disadvantages are ambient temperature limitation, sluggish methanogen microorganism growth, and high detention time. Anaerobic fermentation can divide into acid production and methane generation. The first stage is facultative or anaerobic microorganism converting protein, carbohydrate, and lipid into organic acids such as acetic acid. The second stage subsequently converts organic acid and alcohol into $\mathrm{CH} 4$ and $\mathrm{CO} 2$. The control environment factors including temperature, $\mathrm{pH}$, toxic substances, mixing, and sludge recycling, and methane production.

Aerobic treatment: Activated sludge process is using aerobic microorganisms including bacteria, fungi, protozoa, and rotifer adsorb, degrade, and treat dissolve and micro particular substances. The mixed liquors are mixed cultures bioflocs.

There are five stages including primary settling basin, aerated tank, second sedimentation basin, recycling sludge and wasted sludge. Piggery toilet can be equipped in front of three stage treatment processes. Piggery toilet can lessen water consumption, increase carbon nitrogen ratio, and enhance methane production. Methane can be reused as power, heat sources, and fuel. The treatment of wastewater

${ }^{\star}$ Correspondence to: T Y Yeh, National University of Kaohsiung, Department of Civil and Environmental Engineering, 700, Kaohsiung University Rd., Nanzih District, Kaohsiung 811, Taiwan, E-mail: tyyeh@nuk.edu.tw

Key words: Piggery waste, manure, soil

Received: December 10, 2019; Accepted: December 23, 2019; Published: December 26, 2019 
from piggery industries in Taiwan is not really attention. Costs and difficulties in operating the system is the limitations that made the treatment of wastewater from piggery industries in Taiwan not widely available.

\section{Piggery waste case studies}

Recently, Taiwan lunched an ambitious project basically reused piggery farm solid and liquid waste to watering agriculture farmland. By virtual the aforementioned approach, it can creates a great deal of benefits and manage waste via this zero discharge. In this paper, the agricultural wastewater can be proper management as well as piggery waste phytoremediation will be addressed.

\section{Background}

Three stage piggery waste water treatment including soil liquid separation, anaerobic digestion and then aerobic treatment which is not well received and popular due to costly and difficult operated I Taiwan. Particularly, the anaerobic component is always a headache.

EPA mandated pig farmer to comply with Effluent standard, will collect water pollution fee from year 2017. Piggery industries need to report their water quality and quantity to the environmental agency, If they fail to comply with the aforementioned policy the penalty will be $60,00-600,00 \mathrm{NT}$. If serious divert their wastewater will be highly punished 20,000,000 NT.

Each pig creates BOD and TN 150 and 20 g per head per day, respectively. Within $3.8 \mathrm{~kg}$ manure produced each day per pig, $375 \mathrm{~g}$ is volatile suspended solid (VS). In Taiwan, 8137 pig farms compass the capacity 5000 heads create 8137 tons organic pollutants and 198 tons total nitrogen per day.

Gas generate from anaerobic segment has never been well collected. Each pig produces 0.1 cubic meter methane while methane is a green house gas and the impact factor to green house effect twenty five times high than carbon dioxide.

\section{Three stages piggery waste treatment processes}

Three stage piggery waste water treatment including soil liquid separation, anaerobic digestion and then aerobic treatment which is not well received and popular due to costly and difficult operated I Taiwan. Particularly, the anaerobic component is always a headache. The primary function of solid liquid separation is scum generation reducing and treatment capacity levying. It separates manure and pie which can lessen treatment laboring significantly. Generally speaking, $15-30 \%$ BOD removal and 50\% SS removal. The screen is $0.5 \mathrm{~mm}$ first following by $0.3 \mathrm{~mm}$. The second screen has trustworthy treatment capability.

\section{Enforcement policy}

Without illegals dumping into water bodies, environmental and agriculture entities cooperate to promote modified piggery manure paddy field direct application.

With comply with the required regulatory criteria, it can relief waste control policy and will not view as soil treatment.

With promote piggery industries and entrepreneur commit to anaerobic digestion, methane creating electricity, green electricity, carbon right holding or selling, economic incentive can be optimistically enhanced.

\section{Action plans}

Start from high capacity piggery farmland willing to comply with the policies as well as anaerobic processes operating properly.

Amend current regulation, hold workshop to promote policies.

EPA refused to subside remolding of private pig farms.

Focus on serious and medium polluted river water segment, TMDL will be enforced.

\section{Anaerobic fermentation}

Anaerobic fermentation can degrade complex organic substance into simple $\mathrm{CH}_{4}-\mathrm{CO}_{2}$ under anoxic condition. The advantages of anaerobic fermentation are low sludge generation, methane resource recovery, high organic loading endurance, great treated water production, save oxygen, killing pathogen and virus. However, the disadvantages are ambient temperature limitation, sluggish methanogen microorganism growth, long detention time. Anaerobic fermentation can divide into acid production and methane generation. The first stage is facultative or anaerobic microorganism converting protein, carbohydrate, and lipid into organic acids such as acetic acid. The second stage subsequently converts organic acid and alcohol into $\mathrm{CH} 4$ and $\mathrm{CO} 2$. The control environment factors including temperature, $\mathrm{pH}$, toxic substances, mixing, and sludge recycling, and methane production [2].

\section{Activated sludge process}

Activated sludge process is using aerobic microorganisms including bacteria, fungi, protozoa, and rotifer adsorb, degrade, and treat dissolve and micro particular substances. The mixed liquors are mixed cultures bioflocs.

There are five stages including primary settling basin, aerated tank, second sedimentation basin, recycling sludge and wasted sludge. Piggery toilet can be equipped in front of three stage treatment processes. Piggery toilet can lessen water consumption, increase carbon nitrogen ratio, and enhance methane production. Methane can be reused as power, heat sources, fuel.

\section{Future challenge}

Shipping and transportation cost will be 57-95 NT per ton for Central collect piggery manure. Piggery farmer cannot afford it. In addition, odor during the transportation also a concern.

The feasible approach is to set a centralized methane production facility to purify, electricity as well as heat generation, and gay for motor [3].

\section{Nitrogen cycle}

The circulation of nitrogen in nature provides nitrogen in various oxidation states for use by different organisms. Therefore, nitrogen is one of the elements essential to the survival of organisms. Of the various nutrient cycles in ecosystems, the nitrogen cycle is extremely critical. Nitrification is one of the key functions of the entire nitrogen cycle. In the natural environment, nitrification occurs mainly through the nitrification capacity of microorganisms. Among all chemical autotrophic bacteria, ammonia-oxidizing bacteria are responsible for the oxidation of ammonia into nitrous acid. By comparison, nitriteoxidizing bacteria are responsible for the oxidation of nitrous acid into nitric acid; some of the nitrification is completed by heterotrophic nitrifying bacteria. 


\section{Ammonia nitrogen treatment of livestock wastewater}

Biodenitrification technology is commonly employed both in Taiwan and internationally. The focus of related research is on improvement of the conventional nitrification-denitrification process. From a microbiological viewpoint, nitrification and denitrification are opposite biochemical reactions. Nitrification occurs through oxidation by nitrite-oxidizing bacteria of ammonia into nitric acid, a process that requires an oxygen supply. By contrast, denitrification is an anaerobic reaction, and denitrifying bacteria reduce nitric acid to nitrogen only under anaerobic conditions. Additionally, when organic matter is present in the environment, autotrophic nitrifying bacteria are less competitive for oxygen and nutrients than heterotrophic microorganisms. The growth speed of autotrophic nitrifying bacteria can be easily surpassed by that of heterotrophic microorganisms; therefore, the bacteria often fail to play their expected role in nitrification. To ensure a smooth denitrification reaction, suitable electron acceptors must be provided to denitrifying bacteria. Recent findings have suggested that ammonia can be directly used as an electron acceptor for denitrification in wastewater treatment; the process is named anaerobic ammonia oxidation (ANAMMOX) and occurs in nature. The process of directly converting NO2- to N2 is referred to as direct denitrification of nitrous acid. In engineering applications, oxygen is usually sent from the aerator to the wastewater treatment tank. Direct denitrification of nitrous acid may be applied to reduce a considerable amount of oxygen supply cost. In addition, said technology can be applied in the sewage systems of metropolitan areas worldwide and to materials such as animal husbandry wastewater, fertilizer plant wastewater, and petrochemical wastewater. In such cases, the operating costs that would be saved would be substantial. Therefore, the potential impact of this novel technology is considerable [4-6].

\section{Groundwater nitrogen cycle and plant/microbial transformation mechanism}

The previous single surface flow or single underground flow of constructed wetlands will gradually be replaced by a treatment train constructed-wetland system similar to a combination of an oxidation pond, surface flow, and underground flow in our school. The waste product treatment efficiency and mechanism are clearly superior to those of the single constructed-wetland system of the past. Vymazal (2007) reviewed the application of constructed wetlands to removal of nitrogen and phosphorus nutrient salt from wastewater. The total nitrogen and phosphorus removal efficiencies were $40 \%-55 \%$ and $40 \%-60 \%$, respectively. Moreover, the treatment train constructedwetland system simultaneously provides an aerobic and anaerobic environment to facilitate nitrification, denitrification, nitrogen fixation, and ANAMMOX and thereby has higher removal efficiency than single systems. Anaerobic ammonium oxidation refers to the reaction of nitrate as an electron acceptor with ammonium to form nitrogen in a hypoxic environment. Methods in which nitrite and ammonium react to form nitrogen also exist; both methods are anaerobic.

\section{Conclusions}

Water was obtained from five groundwater monitoring wells: the wells of the Hung-Mao-Hsing, San-Chiu, Yu-Chun, Shih-Chin, and Tsai-Hung livestock farms (at Liouhe, Datong, Heping, Datun, and Erlun elementary schools, respectively). Water quality monitoring data from 2014 to 2018 were compiled, and the data revealed that the groundwater was not affected by heavy metals.

In the groundwater used for irrigation of the farmlands in Dazhuang section (i.e., parcel numbers: 212-2 and 514), copper and zinc were not discovered. This showed that irrigation of farmlands did not pollute the groundwater.

The copper and zinc concentrations in the liquid digestate produced on the San-Chiu livestock farm during the solid-liquid separation process were $190(>120)$ and $986(>260) \mathrm{mg} / \mathrm{kg}$, respectively. This indicates that the copper and zinc concentrations exceeded the standard of heavy metal content in edible crop soil.

Using the San-Chiu livestock farm as an example, the nitrogen concentration in pig liquid digestate was $0.0901 \%$, corresponding to 523.8 tons of pig liquid digestate per hectare annually. The upper limit of heavy metal accumulation in farmlands with liquid or fiber digestate was 1,732 and 1,622 years for copper and zinc, respectively. The upper limit of heavy metal accumulation in liquid digestate-irrigation farmland was calculated to be 80 years (copper) and 26 years (zinc). The SS concentration in the mixed liquid digestate and fiber digestate was $200-5,000 \mathrm{mg} / \mathrm{L}$, and the upper limit of heavy metal accumulation in irrigation farmland was calculated to be $318-1,470$ years (copper) and 115-1,097 years (zinc).

When the nitrogen content of liquid digestate is low, more liquid digestate is required for irrigation; this easily results in heavy metal accumulation and shortens the irrigation service life.

Soils with liquid or fiber digestate are more favorable for rose growth than do soils without any digestate. The poor growth of the roses may have been caused by the soil fertility (nitrogen, phosphorus, and potassium) in the experiment. The EC was $600 \mu \mathrm{s} / \mathrm{m}$, which is the threshold value above which salt injury occurs in normal crops. The infiltration pressure that occurs when the EC threshold is exceeded affects the root system's absorption of soil moisture, which is unfavorable for the growth of crops.

\section{References}

1. Su JJ, Liu BY, Chang YC (2003) Emission of greenhouse gas from livestock waste and wastewater treatment in Taiwan. Agr Ecosyst Environ 95: 253-263.

2. Yeh TY (2016) A study on integrated phytoremediation measures for enhancing energy crops' performance in treating heavy metal-polluted soil. Journal of Soil and Groundwater Remediation 3: 183-190.

3. Yeh TY (2017) Biostimulator and biodegradable chelator to pytoextract stubborn soil $\mathrm{Pb}$ and Ni. Journal of the Taiwan Institute of Chemical Engineers 71: 174-188.

4. Yeh TY (2015) Chelator-enhanced phytoextraction of copper and zinc by sunflower Chinese cabbage, cattails and reeds. International Journal of Environmental Science and Technology 12: 327-340. $\square$

5. Yeh TY (2017) Intergated phytoremediation focused on microbial investigation. RCS.

6. Yeh TY (2017) Conservative heavy metals total discharge schemes. Environmental Science and Pollution Research.

Copyright: $(02019$ Chen WC. This is an open-access article distributed under the terms of the Creative Commons Attribution License, which permits unrestricted use, distribution, and reproduction in any medium, provided the original author and source are credited. 